\title{
Influence of temperature variation on Seismic subsidence properties of frozen soil
}

\author{
LIU Ya ${ }^{1, a}$, JIANG Ning-shan* 1,b ${ }^{\text {LI Hong-wei }}{ }^{2, \mathrm{c}}$ and LI Hui ${ }^{1, \mathrm{~d}}$ \\ ${ }^{1}$ Qinghai University, Xining 810000, China \\ ${ }^{2}$ College of Hydraulic and Civil Engineering, Tarim University, Aral 843300, China. \\ aliuya0809@outlook.com, ㅁhjns@163.com, zjulhw@163.com, ⒈1992808903@qq.com
}

Keywords: Frozen soil; temperature gradient; ambient negative temperature; Seismic subsidence; dynamic loading

Abstract. To reduce the engineering geological disasters in permafrost regions and improve the durability of highways and railways. The dynamic load test of a certainly frozen soil roadbed in the G214 highway is carried out by taking the initial environment negative temperature gradient as the control variable for study the vibration and subsidence characteristics of frozen soil under temperature variation. Results show that the frozen soil is more prone to collapse at the same temperature than the rising frozen soil. The lower the negative temperature of the initial environment is, the more easily the frozen soil will become; As the temperature gradient increases, the temperature rise of frozen soil is greater than that at the same temperature, and the difference increases first and then decreases gradually to 0 . When the frozen soil temperature rises from the initial environment temperature to above 0 , the vibration settlement is nearly the same. In the design of roadbed in permafrost region, a comprehensive analysis and design should be taken considering the negative temperature gradient of the initial environment.

\section{Introduction}

On the construction of the roadbed of Qinghai Tibet highway, railway and other large engineering projects, and cyclic loading will directly affect the service life of the building and safety engineering in permafrost, which under the dynamic load settlement is one of the hazards. Seismic subsidence refers to the additional settlement produced by soil under certain cyclic loading ${ }^{[1]}$. In the study of road engineering settlement, a commonly used method is based on the axial load in the static mode analysis of subgrade settlement and deformation ${ }^{[2]}$, for the study of frozen soil under dynamic loading settlement is less, especially the characteristics of frozen soil under the change of temperature in the vibration research. In the China distribution of permafrost region accounted for about 53\%, and the Qinghai Tibet plateau area to the total area of China's permafrost region $70 \%{ }^{[3-4]}$, permafrost engineering disaster is very serious.

The temperature difference between the day and the night in the Qinghai Tibet Plateau is high. Due to the influence of global warming, the warming rate of the Tibetan Plateau has reached $0.3^{\circ} \mathrm{C} / 10 \mathrm{a}$ in recent 50 years ${ }^{[5-6]}$. The nearer the study period is, the greater the temperature tendency is, the more obvious the warming is in the near future ${ }^{[7]}$. It is expected to rise by $2.2 \sim 2.6^{\circ} \mathrm{C}$ degrees by $2050^{[8]}$. The influence of temperature change on frozen soil is especially prominent, so it is necessary to study the influence of dynamic load on frozen soil subsidence under temperature variation.

Although the researchers have explored, the frozen soil is more complex, the study of frozen soil is far from enough. The nature of the frozen soil is greatly affected by temperature, so it is very important to study the influence of dynamic load on the properties of frozen soil under temperature change. In this experiment, a new type of three axle tester is used to consolidate soil samples under small confining pressure. Freezing of the consolidated soil sample under the confining pressure is carried out at the preset temperature, and finally, the dynamic loading test is carried out. It can more realistically reveal the cumulative strain development law of frozen soil under dynamic loading, and 
study the influence of temperature on the vibration sinking property, so as to provide a reference for engineering design, calculation, and construction of frozen soil area in Qinghai.

\section{Test introduction}

Test instruments

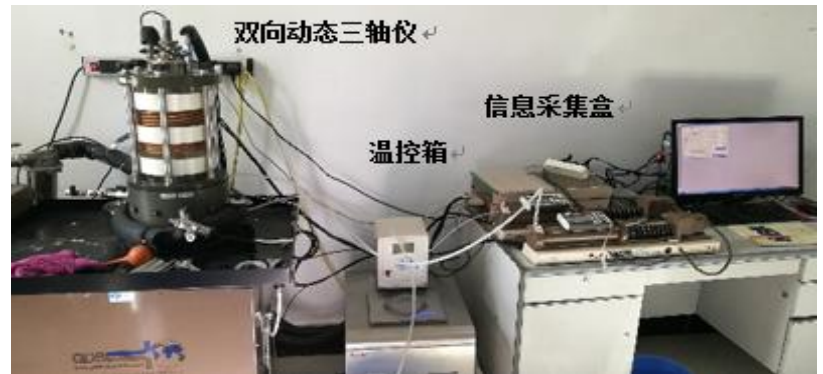

The instrument used in this test is GDS's DYNTTS two-way dynamic three-axis test platform, as shown in Figure 1. This instrument has a precise control mode and does not need to be modified. Its accuracy fully satisfies the requirements of this test.

Fig.1 Instrument Platform Diagram

\section{Test material}

The test soil is 3800 meters above sea level in Qinghai Province, Hainan Tibetan Autonomous Prefecture Heka mountain building foundation pit soil. The depth is the foundation depth, the soil type is silty loess, the soil particles are smaller, and the actual moisture content is $11 \%$, which is the soil moisture content of this test. The soil samples are dried, rolled and screened to remove soil particles larger than $2 \mathrm{~mm}$ and retain the parts below $2 \mathrm{~mm}$ as soil for testing. Their physical properties are shown in table 1.

Table 1 Physical parameters

\begin{tabular}{|c|c|c|c|c|c|c|c|c|c|c|}
\hline \multirow[b]{2}{*}{ Name } & \multirow[b]{2}{*}{$\omega_{L / \%}$} & \multirow[b]{2}{*}{$\omega_{P / \%}$} & \multirow[b]{2}{*}{$\rho_{d \max } / \mathrm{cm}^{3}$} & \multirow[b]{2}{*}{$\mathrm{Cu}$} & \multirow[b]{2}{*}{$\mathrm{Cc}$} & \multicolumn{5}{|c|}{ Soil particle distribution $/ \%$} \\
\hline & & & & & & $\begin{array}{c}0.25 \sim 0.07 \\
5 \\
\end{array}$ & $0.75 \sim 0.05$ & $0.05 \sim 0.01$ & $0.01 \sim 0.005$ & $<0.005$ \\
\hline Silty clay & 22.5 & 13.5 & 1.7 & 18.7 & 4.0 & 13.2 & 33.5 & 35.6 & 4.9 & 12.8 \\
\hline
\end{tabular}

Sample preparation

In accordance with the "Specification of soil test " test method for soil weighed according to the moisture content of soil, add appropriate amount of water, soil and water after mixing evenly in a sealed dish, placed a day, to ensure that the soil water in different positions after wetting rate difference specification ${ }^{[9]}$. According to the dry density requirement, the soil layer is compacted into a sample with a diameter of $39.1 \mathrm{~mm}$ and height of $80 \mathrm{~mm}$.

\section{Test scheme}

The soil samples of this test are equal pressure consolidation. The main variable is the negative temperature gradient of the initial environment. The concrete scheme is shown in Table 2.

In this study, the seismic subsidence characteristics of frozen soil after heating are studied. The reason for the change is that after the increase of the environmental temperature, the water produced by melting ice in the soil can not be discharged in time, resulting in some of the soil particles change into the mud, which can not withstand any load. This time is very short, and if after a period of melting water discharge, the soil skeleton will adjust itself to balance the soil particles and pores, then the test will be meaningless. Therefore, when the soil temperature rises to the set temperature and is stable, the test needs to be carried out quickly. The test adopts the method of step by step loading, and the loading mode adopts sine wave. Because of the limitation of the instrument condition, the starting point of each loading stage is half of the dynamic stress amplitude. Each stage vibration 10 times, the first stage amplitude is $50 \mathrm{kPa}$, then each level increases $50 \mathrm{kPa}$ until the soil sample strain reaches $5 \%$. 
Through the static load test, it is found that after the strain of the frozen soil is $5 \%$, the stress will not increase any more. Therefore, the test takes $5 \%$ of the standard of destruction.

Table 2 Test schemes for major variables

\begin{tabular}{ccccc}
\hline $\begin{array}{c}\text { Initial ambient } \\
\text { negative } \\
\text { temperature }\left({ }^{\circ} \mathrm{C}\right)\end{array}$ & $\begin{array}{c}\text { Temperature of } \\
\text { constant } \\
\text { temperature } \\
\text { group }\left({ }^{\circ} \mathrm{C}\right)\end{array}$ & $\begin{array}{c}\text { Temperature after } \\
\text { heating }\left({ }^{\circ} \mathrm{C}\right)\end{array}$ & $\begin{array}{c}\text { Confining } \\
\text { pressure }(\mathrm{kPa})\end{array}$ & $\begin{array}{c}\text { Frequenc } \\
\mathrm{y}(\mathrm{Hz})\end{array}$ \\
\hline-15 & -15 & $-10 、-5 、 0$ & & \\
-10 & -10 & $-5,0$ & & \\
-5 & -5 & $-2 、 0$ & 150 & \\
-2 & -2 & none & & \\
0 & 0 & none & & \\
\hline
\end{tabular}

\section{Test results and analysis}

In this study, the influence of these factors on the vibration and subsidence characteristics of frozen soil is studied by studying the frozen soil under different initial environment, negative temperature, temperature gradient, confining pressure and frequency. The following is the impact analysis.

\section{Environmental negative temperature influence}

Fig. 2 is a diagram of a test group of constant temperature frozen soil, which is a test group which directly applies dynamic load after freezing at the initial freezing temperature. As can be seen from Figure 2, the higher the permafrost temperature in the region, the faster the cumulative strain increases with the series, the easier it is to collapse. The reason for this phenomenon is that the higher the temperature, the fewer ice crystals, the weaker the cementation of ice to the soil, the lower the strength of the frozen soil and the faster the strain grows.

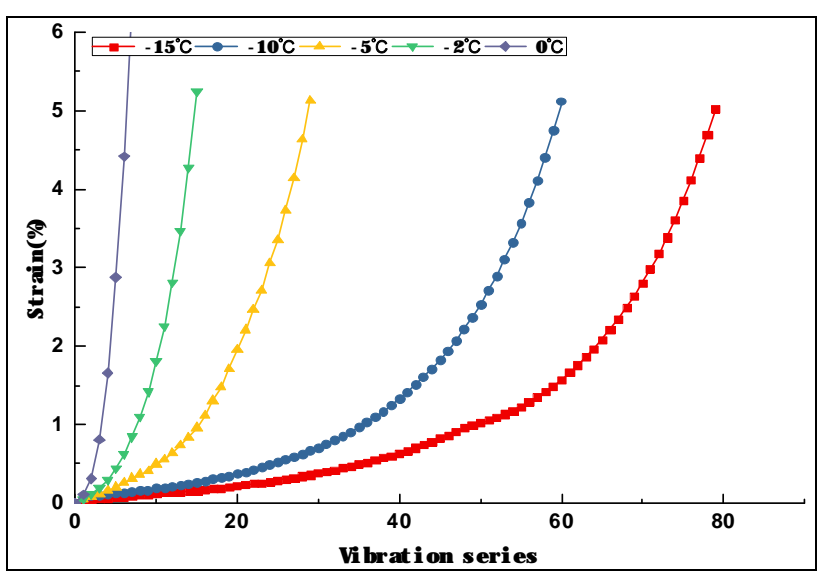

Fig.2 Temperature test without change

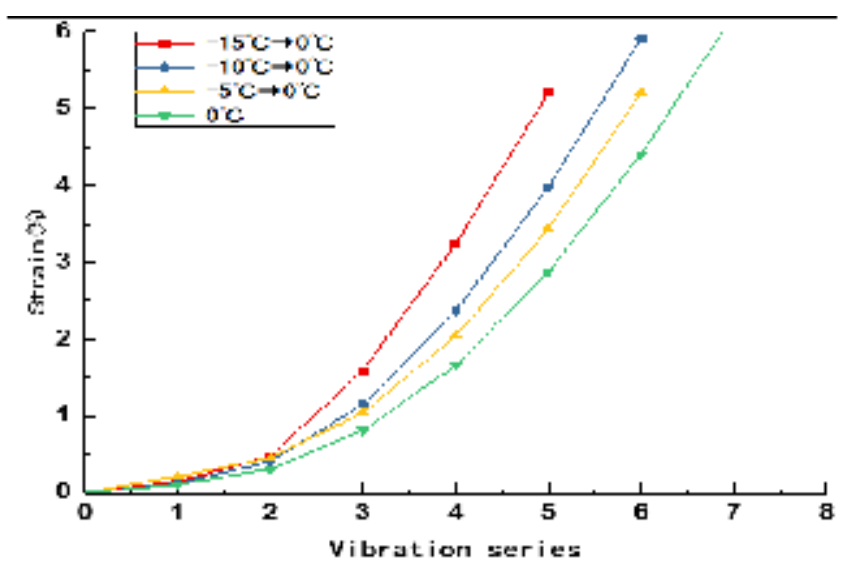

Fig.3 Negative temperature influence Diagram

Fig. 3 compares the curves of the negative temperature of different initial environments to the same temperature.It can be seen that:

(1) At the same temperature, the accumulated strain of the heating-up frozen soil increases faster than that of the constant frozen soil, and the vibration depression is severe;

(2) The lower the initial negative temperature of the frozen soil, the faster the cumulative strain increases with the increase of series, and the shock of frozen soil after heating is more intense

The cause of this phenomenon is the frozen soil with temperature stability, in which the ice is a dense and orderly structure, the ice molecules are more stable, and the strength of frozen soil is correspondingly higher. As the permafrost increases, the activity of ice molecules increases, which results in the recombination between ice molecules and reduces the cementation between molecules. 
Eventually, the resulting permafrost is more prone to collapse at this temperature than at constant temperatures. At the same time, the frozen soil is affected by the initial environmental temperature, resulting in different ice content in the soil. The ice crystal content of frozen soil with lower temperature is higher than that of the frozen soil with higher temperature. Therefore, during the same temperature rise, the recombination between frozen soil and ice molecules at lower initial environmental temperature is more severe, which makes the frozen soil with lower initial negative temperature more likely to collapse.

\section{Effect of temperature gradient}

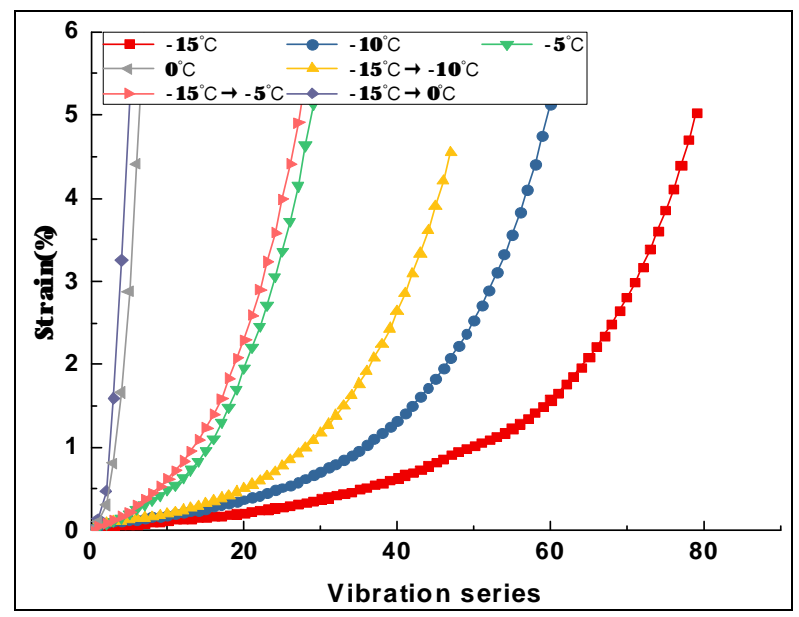

Fig.4 Influence of temperature gradient on frozen soil of heating-up
Fig. 4 is the same as the negative temperature of the initial environment in three groups, and the contrast chart of temperature gradient curves. The curves are compared with the temperature rise of frozen soil and constant frozen soil at the same temperature. As can be seen from the graph:

(1) At the same temperature, the frozen soil at elevated temperature is more likely to collapse than the constant frozen soil.

(2) At the same temperature, the accumulated strain value of the temperature constant frozen soil is deducted from the accumulated strain value of each dynamic load of the frozen soil

of temperature rises, and the difference is obtained. The difference increases first with the increase of temperature gradient, then decreases gradually, and finally becomes 0 . When the frozen soil temperature rises from the initial environment to 0 degrees above, the curve is basically coincident with the constant temperature frozen soil curve at 0 degrees centigrade.

The reason for this phenomenon is that during the rapid warming of frozen soil, the pore ice gradually melts. As the pore ice melting rate is rapid, the water produced can not be discharged in time, the soil skeleton can not adjust itself in time to adapt to the new equilibrium pore ratio. This results in a part of the soil in the frozen soil that becomes mud, which in turn does not support any form of loading and produces a greater cumulative strain. Moreover, in the initial heating stage, the greater the temperature gradient, the more the amount of melt-water in the soil than the discharge, the more internal mud, the greater the strength loss, the greater the cumulative strain. As the temperature gradient increases and time increases, the water produced by melting ice is in close balance with the discharged water. The soil skeleton is gradually adjusted and adapted to the new equilibrium void ratio so that the cumulative strain rate slows down and gradually approaches the cumulative strain rate of permafrost at a constant temperature. When the temperature rises to over $0^{\circ} \mathrm{C}$, the soil has only its own strength, such as inter particle friction and cohesion, and its properties are independent of temperature so that the frozen soil with elevated temperature coincides with the frozen soil curve of constant temperature.

\section{Conclusions}

(1) Because the warming of the permafrost causes the recombination of ice molecules and reduces the cementation of the molecules, the frozen soil that heats up is more likely to collapse at the same temperature than the frozen soil at a constant temperature. The initial environmental negative temperature of the frozen soil affects the amount of ice contained in the frozen soil, resulting in the lower temperature of the initial environment of warming frozen soil, and the more likely the permafrost will collapse. 
(2) The warming gradient of permafrost influences the relationship between the yield of ice melt-water and the discharge volume, which results in the difference of the accumulated strain growth rate of the frozen soil. At the same temperature, the accumulated strain value of the temperature constant frozen soil is deducted from the accumulated strain value of each dynamic load of the frozen soil of temperature rises, and the difference is obtained. The difference increases first with the increase of temperature gradient, then decreases gradually, and finally becomes 0 . When the frozen soil temperature rises from the initial environment to 0 degrees above, the curve is basically coincident with the constant temperature frozen soil curve at 0 degrees centigrade.

(3) The initial environmental negative temperature and temperature gradient have a great influence on the earthquake resistance of the permafrost. Therefore, in the design of roadbed in the tundra, it is important to pay attention to temperature change in order to avoid the failure of the roadbed. The initial environment should be combined with weather data, consider not only the local negative temperature, and analyze the temperature gradient, and comprehensive analysis before design, otherwise easy to cause the permafrost pumping road pavement frost heave.

\section{Acknowledgements}

This work was supported by science and technology Department of Qinghai Province, China(Grant No. 2015-ZJ-722 and 2016-ZJ-766), the National Natural Science Foundation of China (Grant No. 51668055) and the Open Fund of State Key Laboratory of Frozen Soil Engineering of China (Grant No. SKLFSE201708).

* is corresponding author

\section{Reference}

[1] YU Shou-song, SHI Zhao-ji, XIE Jun-fei, et al. Analysis of permanent deformation for tunnel of Shanghai underground[J]. Earthquake Engineering \& Engineering Vibration, 1986, 6(1): 51-60. (in Chinese)

[2] WANG Miao, MENG Shang-jiu, WANG Xing-long, et al. Experimental research on development of vibration excited subsidence of frozen soil under cyclic loading $[\mathrm{J}]$. Chinese Journal of Geotechnical Engineering, 2016, 38(05): 916-922. (in Chinese)

[3] MENG Shang-jiu, CHENG You-kun. The review on permanent deformation of seasonal frozen soil subgrade under the action of vehicle load[J]. Journal of Harbin University of Science \& Technology, 2014, 19(2): 1-5. (in Chinese)

[4] ZHOU You-wu, GUO Dong-xin, QIU Guo-qing, et al. Frozen ground of China[M]. Beijing: Science Press, 2000: 1-10. (in Chinese)

[5] YAO Yi-bin, LEI Xiang-xu, ZHANG Liang, et al. Analysis of precipitable water vapor and surface temperature variation over Qinghai-Tibetan Plateau from 1979 to 2014[J]. Chinese Science Bulletin, 2016, 61(13): 1462-1477. (in Chinese)

[6] Jiang Y J, Li S J, Shen D F, et al. Climate change and its impact on the lake environment in the Tibetan Plateau in 1971-2008, Sci Geogr Sin, 2012, 32: 1503-1512. (in Chinese)

[7] Li Lin, Chen Xiao-guang, Wang Zhen-yu et al. Climate Change and Its Regional Differences over the Tibetan Plateau. Advances in Climate Change Research, 2010,6(3):181-186. (in Chinese)

[8] Qin Da-he. Assessment of environmental evolution in Western China. Beijing: Science Press, 2002. (in Chinese) 
[9] SL237-1999 Specification of soil test[S]. 1999. (in Chinese) 